\title{
Developmental Control of Oocyte Maturation and Egg Activation in Metazoan Models
}

\author{
Jessica R. Von Stetina and Terry L. Orr-Weaver \\ Whitehead Institute and Department of Biology, Massachusetts Institute of Technology, Cambridge, \\ Massachusetts 02142 \\ Correspondence: weaver@wi.mit.edu
}

Production of functional eggs requires meiosis to be coordinated with developmental signals. Oocytes arrest in prophase I to permit oocyte differentiation, and in most animals, a second meiotic arrest links completion of meiosis to fertilization. Comparison of oocyte maturation and egg activation between mammals, Caenorhabditis elegans, and Drosophila reveal conserved signaling pathways and regulatory mechanisms as well as unique adaptations for reproductive strategies. Recent studies in mammals and C. elegans show the role of signaling between surrounding somatic cells and the oocyte in maintaining the prophase I arrest and controlling maturation. Proteins that regulate levels of active Cdk1/ cyclin B during prophase I arrest have been identified in Drosophila. Protein kinases play crucial roles in the transition from meiosis in the oocyte to mitotic embryonic divisions in C. elegans and Drosophila. Here we will contrast the regulation of key meiotic events in oocytes.

G erm cells exist to produce gametes. Gametogenesis has two crucial events: meiosis and differentiation to produce the specialized features of gametes. In meiosis, two rounds of chromosome segregation occur without an intervening round of DNA replication. The resulting reduction of chromosome number is essential so that fusion of the sperm and egg genomes at fertilization restores a diploid chromosome number. In spermatogenesis, differentiation of sperm follows meiosis. In contrast, oocyte differentiation occurs during meiosis, necessitating arrest and restart of meiosis.

In addition to differences in timing of differentiation relative to meiosis, the distinct differentiated characteristics of sperm and oocytes reflect their unique contributions to fertilization and early embryogenesis. The mature oocyte contains maternal components needed by the fertilized embryos until developmental regulation comes under zygotic control. Although this can be as early as the two-cell stage in mammals, in other animals up to 14 division cycles of early embryogenesis are under maternal control, driven by proteins and mRNAs that must be stockpiled during oogenesis (Tadros et al. 2007). Moreover, patterning of the body axes is laid down in the developing oocyte in some animals (Riechmann and Ephrussi 2001). In contrast to the "moving van" nature of the oocyte, in most organisms the sperm is differentiated as a "race car," with minimal cytoplasm

Editors: Paolo Sassone-Corsi, Margaret T. Fuller, and Robert Braun

Additional Perspectives on Germ Cells available at www.cshperspectives.org

Copyright (C) 2011 Cold Spring Harbor Laboratory Press; all rights reserved; doi: 10.1101/cshperspect.a005553

Cite this article as Cold Spring Harb Perspect Biol 2011;3:a005553 
J.R. Von Stetina and T.L. Orr-Weaver

and adaptations to be motile and capable of penetrating the egg.

In most animals, oocyte development involves arrest of meiosis at two points, permitting growth, differentiation, and coordination between fertilization and the completion of meiosis (Fig. 1). Differentiation of the oocyte and stockpiling of maternal components occurs during a prolonged arrest in prophase I, the primary arrest point. Oocyte maturation releases this arrest, enabling the oocyte to progress into the meiotic divisions. The secondary arrest point coordinates completion of meiosis with fertilization, and the meiotic stage of this arrest varies between animals (Fig. 1). In most vertebrates, the arrest occurs at metaphase of meiosis II, in insects metaphase of meiosis I, in marine invertebrates such as starfish it is in G1 after the completion of both meiotic divisions, whereas in C. elegans, sperm signaling triggers oocyte maturation and there is not a secondary meiotic arrest (Nishiyama and Kishimoto 2010).

Extrinsic cues link developmental input with progression through meiosis in differentiating oocytes. These signals promote the onset, maintenance, and release of the primary arrest as well as the onset and maintenance of the secondary arrest. Long-range hormonal signals affect oocyte maturation and the release of the primary arrest, but local signaling also occurs. Cell-cell interactions between the oocyte and somatic support cells are crucial in regulating oocyte maturation and, in C. elegans, signaling from the sperm plays a critical role.

In general, animals make a tremendous investment in oocyte production and they are in limiting supply, making proper regulation of oogenesis vital for reproductive success. Here we discuss recent discoveries on the developmental control of oocyte maturation and egg activation and the extrinsic signals coordinating meiosis with oocyte differentiation. We compare vertebrates, focusing largely on mammals, with the invertebrate models $C$. elegans and Drosophila (Table 1). Production of functional oocytes also requires mechanisms to ensure accurate chromosome segregation in the meiotic divisions, but we will not cover this topic here. In addition, regulation of the translation of stockpiled maternal mRNAs is critical, contributing to the developmental timing of both

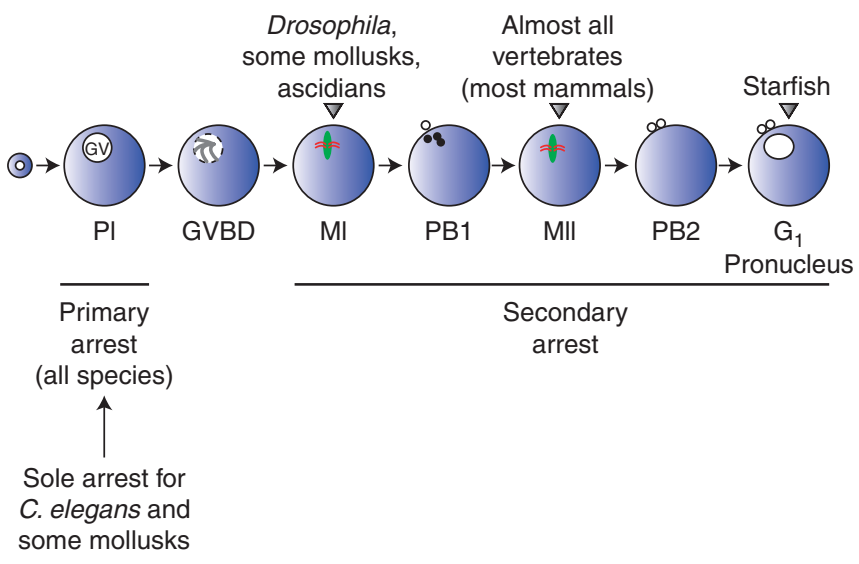

Figure 1. Meiotic arrests during oocyte development. Oocytes from most species undergo a first arrest at prophase I (PI) that is maintained for a few days (Drosophila) or for decades (humans). On hormonal or developmental stimulation, oocytes undergo meiotic maturation, release the primary arrest, and enter a second arrest at metaphase I (MI), metaphase II (MII), or postmeiotic $\mathrm{G}_{1}$ depending on the species. Fertilization triggers release from the second arrest and the completion of meiosis in vertebrates (Xenopus and mammals). Drosophila releases the secondary arrest in a sperm-independent manner. GV, germinal vesicle; PI, prophase I; GVBD, germinal vesicle breakdown; MI, metaphase I; PB1, polar body 1; MII, metaphase II; PB2, polar body 2. (Adapted from Sagata 1996; reprinted with express permission from Noriyuki Sagata.) 
Developmental Control of Oocyte Maturation and Activation

Table 1. Summary of key molecular players and events regulating oocyte meiotic arrest, maturation, and egg activation

\begin{tabular}{|c|c|c|c|}
\hline Meiotic event & Mouse & Drosophila & Caenorhabditis elegans \\
\hline Primary arrest point & Prophase I & Prophase I & Prophase I \\
\hline $\begin{array}{l}\text { Length of prophase I } \\
\text { arrest }\end{array}$ & Months & $\sim 1.5 \mathrm{~d}$ & $\begin{array}{l}\sim 23 \text { min }(\text { when } \sim 40 \\
\text { sperm are present }) \\
\sim 8-10 \text { h (no sperm } \\
\text { present) }\end{array}$ \\
\hline $\begin{array}{l}\text { Maintenance of } \\
\text { prophase I arrest }\end{array}$ & $\begin{array}{l}\text { High cAMP produced } \\
\text { by the oocyte; low } \\
\text { Cdk1 activity }\end{array}$ & $\begin{array}{l}\text { Low cyclin A; Elgi, Mtrm; } \\
\text { inhibition of Polo; } \\
\text { inactive Cdk2/Cyclin E }\end{array}$ & $\mathrm{G} \alpha_{\mathrm{o} / \mathrm{i}}$ \\
\hline $\begin{array}{l}\text { Maturation } \\
\text { induction signal }\end{array}$ & $\mathrm{LH}$ & Unknown & MSP \\
\hline $\begin{array}{l}\text { Function of } \\
\text { surrounding } \\
\text { somatic cells for } \\
\text { meiotic progression }\end{array}$ & $\begin{array}{l}\text { Granulosa cells } \rightarrow \\
\quad \text { transport of cGMP }\end{array}$ & Unknown & $\begin{array}{l}\text { Gonadal sheath cells } \rightarrow \\
\text { high cAMP }\end{array}$ \\
\hline $\begin{array}{l}\text { Somatic cell/oocyte } \\
\text { communication }\end{array}$ & $\begin{array}{l}\text { Transport of cGMP } \\
\text { through gap } \\
\text { junctions }\end{array}$ & Unknown & $\begin{array}{l}\text { Transport of unknown } \\
\text { molecule through gap } \\
\text { junctions }\end{array}$ \\
\hline $\begin{array}{l}\text { Secondary arrest point } \\
\text { Secondary arrest } \\
\text { mechanism }\end{array}$ & $\begin{array}{l}\text { Metaphase II } \\
\text { cMOS; active MAPK; } \\
\text { high Cdk1/Cyclin } \\
\text { B; Emi2 inhibition } \\
\text { of APC }\end{array}$ & $\begin{array}{l}\text { Metaphase I } \\
\text { Presence of chiasmata; } \\
\text { heterochromatin pairing; } \\
\text { chromosome congression } \\
\text { to metaphase plate; } \\
\text { inactive APC?; high } \\
\text { Cdk1/Cyclin B?; SAC }\end{array}$ & $\begin{array}{l}\text { None } \\
\mathrm{N} / \mathrm{A}\end{array}$ \\
\hline $\begin{array}{l}\text { Egg activation } \\
\text { Completion of meiosis }\end{array}$ & $\begin{array}{l}\text { Requires fertilization } \\
\text { Inactivation of Emi2; } \\
\text { activation of APC; } \\
\mathrm{Ca}^{2+} \text { signaling; } \\
\text { CamKII }\end{array}$ & $\begin{array}{l}\text { Fertilization-independent } \\
\text { cortex form of APC } \\
\text { sarah }\left(\mathrm{Ca}^{2+} ?\right)\end{array}$ & $\begin{array}{l}\text { Requires fertilization } \\
\text { EGG4,5 pseudo tyrosine } \\
\text { phosphatase; APC } \\
\text { activity }\end{array}$ \\
\hline
\end{tabular}

LH, luteinizing hormone; MSP, major sperm protein; cGMP, guanosine $3^{\prime}-5^{\prime}$-cyclic monophosphate; MAPK, mitogenactivated protein kinase; APC, anaphase-promoting complex.

oocyte maturation and egg activation (reviewed in Vardy and Orr-Weaver 2007b; Radford et al. 2008). A detailed review on mammalian oocyte maturation is available (Jaffe and Norris 2010). Two comprehensive reviews on egg activation and release of the secondary meiotic arrest also have been published recently (Horner and Wolfner 2008; Nishiyama and Kishimoto 2010).

\section{MAMMALS}

Recent progress in our understanding of the control of meiosis in mammalian oogenesis has highlighted the importance of signaling between the oocyte and surrounding somatic follicle cells. The cell cycle regulators affected by this signaling were identified and their roles in oocyte maturation and maintenance of the secondary arrest largely elucidated from studies using Xenopus. In this article, we focus on mammalian oocytes but draw parallels to the regulation identified in Xenopus.

\section{Maintenance of the Primary Arrest}

The mammalian oocyte enters meiosis during fetal development and arrests at the diplotene stage of prophase I (germinal vesicle [GV] state) from birth to puberty (Fig. 2A) (Hunt and 
J.R. Von Stetina and T.L. Orr-Weaver

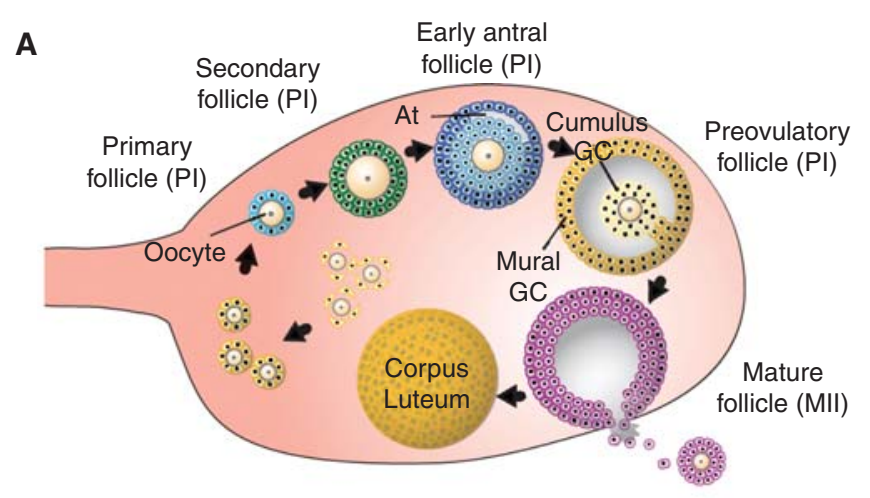

B

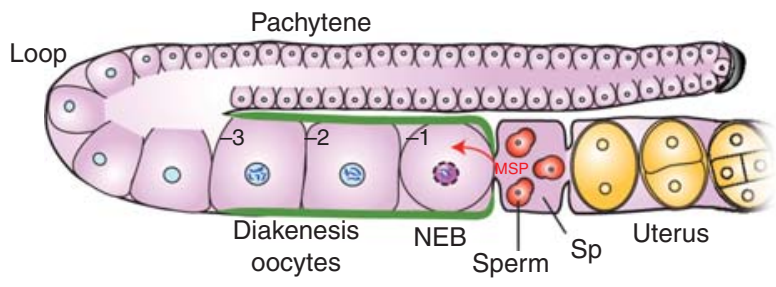

C

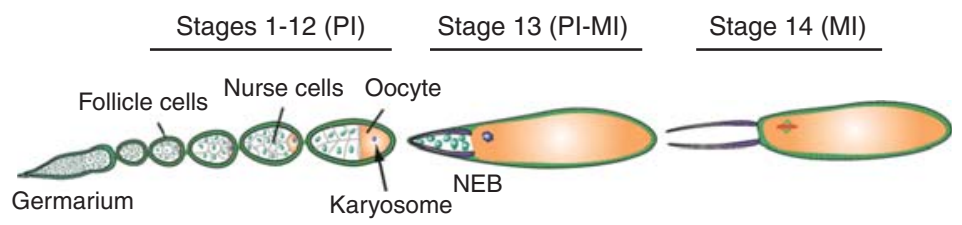

Figure 2. Stages of oocyte development and meiotic progression. (A) In mammals, a primary follicle, consisting of a prophase I (PI) arrested primary oocyte surrounded by somatic pregranulosa cells, is generated shortly after birth. Primary oocytes grow, whereas granulosa cells (GC) proliferate to form secondary follicles. As a fluid-filled cavity (antrum, At) begins to form, secondary follicles become early antral follicles. In preovulatory follicles, the fully grown primary oocyte is surrounded by cumulus and mural granulosa cells. After a luteinizing hormone surge, the oocyte undergoes meiotic maturation and produces a secondary oocyte that arrests at metaphase II (MII). During ovulation, the MII oocyte is released into the oviduct where on fertilization, meiosis is resumed and completed. (B) In the distal germline of $C$. elegans, syncytial nuclei enter meiosis and are found in pachytene of PI. Around the loop region, these nuclei cellularize to form oocytes that progress to diakenesis I where they arrest. Somatic-derived gonadal sheath cells (green) surround the developing oocytes. In response to sperm and its secreted factor major sperm protein (MSP), the most proximal oocyte $(-1)$ is induced to undergo meiotic maturation (nuclear envelope breakdown [NEB] and rounding up of the cell). The oocyte passes through the spermatheca (Sp) where fertilization occurs, and it then is deposited into the uterus as a one-cell zygote. $(C)$ The Drosophila oocyte develops within a 16-cell germline cyst surrounded by a monolayer of somatic follicle cells (green). The oocyte enters meiosis in region $2 \mathrm{~A}$ of the germarium and soon after arrests at PI for most of oogenesis $(\sim 2 \mathrm{~d})$. At stage 13 , after a yet unknown developmental or hormonal signal, the oocyte undergoes meiotic resumption and progresses into metaphase I (MI), the secondary arrest point. On ovulation, as the mature stage 14 oocyte travels in the oviduct, rehydration and mechanical pressure trigger the completion of meiosis. (A, Adapted from Matzuk and Lamb 2002; reprinted with express permission from Martin Matzuk. B, Adapted from Kuwabara 2003; reprinted with express permission from Patty Kuwabara. C, Adapted from Xiang et al. 2007; reprinted with express permission from Scott Hawley.) 
Hassold 2008). The oocyte remains arrested at this stage for months (mouse) or decades (humans) until a preovulatory hormonal surge (Table 1) (Whitaker 1996; Kishimoto 2003). Because the maturation or M-phase promoting factor (MPF), a complex of the kinase subunit Cdk1 (also known as Cdc2) and the regulatory subunit Cyclin B, triggers the onset of the meiotic divisions, low Cdk1/Cyclin B activity is key in maintaining the prophase I arrest (Sagata 1996). One mechanism to inactivate Cdk1/Cyclin B involves the reduction of Cyclin B levels in GV oocytes by the Anaphase Promoting Complex/Cyclosome (APC/C) and its coactivator Cdh1 (APC ${ }^{\mathrm{Cdh} 1}$ ) (Reis et al. 2006). High levels of the second messenger molecule cyclic adenosine $3^{\prime}, 5^{\prime}$-monophosphate (cAMP) within the mammalian oocyte also are essential to keep Cdk1/Cyclin B in an inactive state during this primary arrest (Mehlmann 2005b). High cAMP levels promote activation of the protein kinase A (PKA) (Conti et al. 2002; Kovo et al. 2006), which concurrently phosphorylates and activates the kinase Weel (a Cdkl inhibitor) (Han et al. 2005) and inactivates the dual-specificity phosphatase Cdc25 (a Cdk1 activator) (Lincoln et al. 2002; Pirino et al. 2009). Thus, cAMP is at the top of a cascade of events leading to the inactivation of Cdk1/ Cyclin B.

The inhibitory cAMP pool that is required to maintain meiotic arrest is produced by the oocyte itself (Fig. 3A) (reviewed in Mehlmann 2005b; Jaffe and Norris 2010). Several lines of evidence have shown that endogenous production of cAMP is mediated by the activation of the $G$ protein $G_{s}$ by the $G$ protein-coupled receptor (GPR3/mouse; GPR12/rat) present on the oocyte plasma membrane and the subsequent stimulation of the adenylyl cyclase (AC), the enzyme responsible for cAMP synthesis (Mehlmann et al. 2002, 2004; Horner et al. 2003; Kalinowski et al. 2004; Freudzon et al. 2005; Hinckley et al. 2005; Mehlmann 2005a; DiLuigi et al. 2008). The crucial role of oocyte pools of cAMP is shown by this source of cAMP being essential for meiotic arrest even when the oocyte is separated from the somatic layer (Vaccari et al. 2008).
In addition to the production of CAMP by the oocyte, somatic-derived inhibitory signals that are transmitted into the oocyte are also required to maintain prophase I arrest (Edry et al. 2006; Jaffe and Norris 2010). Mammalian oocytes develop within a follicle, surrounded by somatic cumulus granulosa cells (inner layer), thus forming an oocyte-cumulus complex (OCC) (Fig. 2A). The OCC connects on one side to somatic mural granulosa cells (outer layer) (Fig. 2A), which are the key source of inhibitory signals (Jaffe and Norris 2010). When this outer layer is removed from the OCC, the oocyte resumes meiosis (Racowsky and Baldwin 1989).

The diffusion of inhibitory signals from the somatic compartment into the oocyte occurs through gap junctions. Consistent with this conclusion, genetic and pharmacological inhibition of gap junctions induce resumption of meiosis (Piontkewitz 1993; Sela-Abramovich et al. 2006; Norris et al. 2008). Guanosine $3^{\prime}, 5^{\prime}$-cyclic monophosphate (cGMP) has been recently identified as an essential inhibitory signal that diffuses through gap junctions from cumulus granulosa cells into the oocyte (Fig. 3A) (Sela-Abramovich et al. 2008; Norris et al. 2009). cGMP inhibits the oocyte-specific cAMP phosphodiesterase 3A (PDE3A), which metabolizes cAMP, and in turn maintains elevated levels of cAMP (Fig. 3A) (Conti et al. 2002; Hambleton et al. 2005; Norris et al. 2009; Vaccari et al. 2009). These studies highlight the conservation of the role of the gap-junction-mediated communication in the control of oocyte meiosis in both vertebrate and invertebrates species (discussed below).

Recent studies have identified a new pathway involved in the generation of cGMP in cumulus granulosa cells and oocytes. It has been shown that the mural granulosa cells stimulate the generation of cGMP by secreting natriuretic peptide precursor type C (NPPC), which binds to and activates the natriuretic peptide receptor 2 (NPR2), a guanylyl cyclase, expressed in the cumulus granulosa cells (Zhang et al. 2010). In addition to producing its own inhibitory pool of cAMP, the oocyte also induces the expression of NPR2 in the cumulus cells (Zhang et al. 2010). 
J.R. Von Stetina and T.L. Orr-Weaver

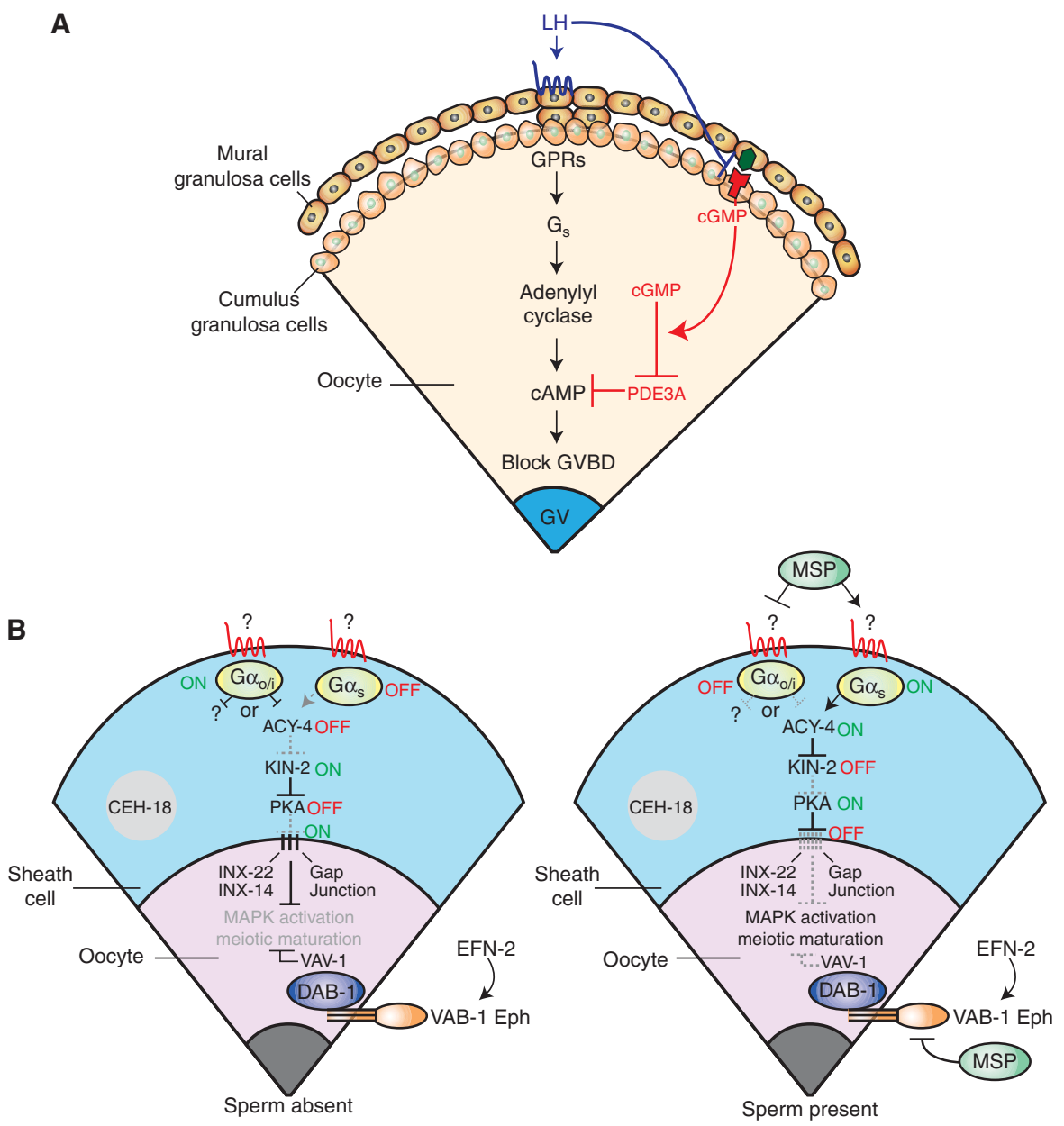

Figure 3. Gap junctional communication between the oocyte and the surrounding somatic cells regulates oocyte meiotic maturation. (A) High levels of cyclic adenosine $3^{\prime}, 5^{\prime}$-monophosphate (cAMP) in the oocyte inhibit meiotic maturation in mammals. The inhibitory cAMP is produced by the oocyte itself via the activation of the GPR3/Gs/adenylyl cyclase pathway. Guanosine 3', 5'-cyclic monophosphate (cGMP) produced by the cumulus somatic cells flows through gap junctions into the oocyte to inhibit PDE3A, the phosphodiesterase responsible for the hydrolysis of cAMP. The oocyte stimulates the expression of natriuretic peptide receptor 2 (NPR2) (red), a guanylyl cyclase, in the cumulus cells. Mural granulosa cells induce the generation of cGMP by secreting the NPR2 ligand, natriuretic peptide precursor type C (NPPC) (green). Binding of luteinizing hormone ( $\mathrm{LH}$ ) to its G protein-coupled receptor (GPCR) (blue) reverses the inhibition of meiotic maturation by decreasing the synthesis of cGMP in the somatic follicular layer and by blocking its diffusion through gap junctions. (B) In C. elegans, the $\mathrm{G} \alpha_{\mathrm{o} / \mathrm{i}}$ pathway in gonadal sheath cells (blue) leads to the inactivation of adenylate cyclase 4 (ACY-4) and subsequently protein kinase A (PKA) in the absence of sperm. This inhibition is postulated to stabilize gonadal sheath-to-oocyte gap junctions composed of innexin (Inx) proteins (Inx-22 and Inx-14), and thereby allow the influx of a negative regulatory signal into the oocyte, which blocks MAP kinase (MAPK) activation and meiotic maturation. In parallel, the VAB-1/Ephrin Receptor in the oocyte inhibits MAPK and oocyte maturation. Sperm-derived major sperm protein (MSP) antagonizes both the sheath $\mathrm{G} \alpha_{\mathrm{o} / \mathrm{i}}$ and oocyte VAB-1 signaling pathways, while simultaneously activating the sheath $\mathrm{G} \alpha_{\mathrm{s}}$ pathway, resulting in MAPK activation and meiotic maturation. It is hypothesized that the $\mathrm{G} \alpha_{s}$ pathway destabilizes sheath-oocyte gap junctions. The nuclear POU homeodomain protein is required for proper differentiation of gonadal sheath cells. (B, Adapted from Govindan et al. 2006 and Sun et al. 2009; reprinted with express permission from Qing-Yuan Sun and David Greenstein, respectively.) 


\section{Meiotic Maturation}

Activation of Cdk1/Cyclin B is the key molecular event that promotes meiotic maturation and release from the prophase I arrest in most species, including mammals (Sagata 1996). The phosphorylation of downstream targets by active Cdk1/Cyclin B leads to nuclear envelope breakdown (NEB) (also known as germinal vesicle breakdown, GVBD), spindle assembly, and chromosome condensation, the morphological hallmarks of meiotic maturation (Jones 2004). In mammals, the onset of oocyte maturation is controlled by the action of the gonadotrophin hormones. Following puberty, in response to a cyclic preovulatory surge in luteinizing hormone $(\mathrm{LH})$, the prophase I-arrested mammalian oocyte resumes meiosis. This is induced by a drop in intraoocyte cAMP concentration, which leads to the activation of the Cdc25 phosphatase and the relief of Cdk1/ Cyclin B inhibition. Because $\mathrm{LH}$ receptors are only expressed in the mural granulosa cells and not in the oocyte (Peng et al. 1991), the LHinduced stimulation of meiotic resumption also involves signaling between the oocyte and its somatic support cells.

Reinitiation of meiosis in response to $\mathrm{LH}$ involves the reduction of cGMP in the oocyte and consequently of cAMP (Fig. 3A). LH mediates this effect in part by decreasing the concentration of cGMP in the mural granulosa cells through a yet not well-understood mechanism (Norris et al. 2009; Vaccari et al. 2009). The second way by which LH reduces cGMP in the oocyte is by inducing the closure of gap junction communication between the somatic cells (Norris et al. 2008, 2009). Activation of the mitogen-activated protein kinase (MAPK) pathway by LH promotes the phosphorylation of connexin 43 (a major ovarian gap junction protein) and induces a decrease in gap junction permeability between the mural granulosa cells (Sela-Abramovich et al. 2005; Norris et al. 2008). This closure of gap junctions prevents the influx of cGMP from the granulosa cells into the oocyte. The resulting reduction of cGMP by these two mechanisms ultimately leads to the release of the inhibition of PDE3A and the increase in cAMP hydrolysis (Norris et al. 2009).

Current evidence indicates that the LHinduced signaling that mediates meiotic maturation is transmitted from the somatic compartment into the oocyte mostly via the activation of the epidermal growth factor (EGF) receptor pathway (Conti et al. 2006; Panigone et al. 2008). Binding of LH to its G protein-coupled receptor in the granulosa cells (Fig. 3A) leads, in part, to the activation of $\mathrm{G}_{\mathrm{s}}$ and the production of cAMP (reviewed in Jaffe and Norris 2010). High cAMP levels in the somatic cells promote PKA activation, and the subsequent synthesis and release of EGF receptor (EGFR) ligands (Panigone et al. 2008). The resulting ligand-dependent transactivation of the EGF receptor is required for the partial activation of MAPK (Panigone et al. 2008), which as discussed above inhibits gap junctions. Activation of the EGFR signaling pathway in response to LH surge also causes a major decrease of cGMP in the granulosa cells (Vaccari et al. 2009).

Regulation of the activity of the APC/C has been shown to be required for the timing of meiotic maturation in mammals. Prior to the onset of meiotic maturation, the phosphatase Cdc14B antagonizes the activity of Cdk1/ Cyclin B by activating Cdh1 and promoting Cyclin B degradation by the APC/C (Schindler and Schultz 2009). Consistent with this role, depletion of Cdc14B by RNAi in GV oocytes causes premature meiotic resumption (Schindler and Schultz 2009). On GVBD, the early mitotic inhibitor 1 (Emil) protein counteracts the function of $\mathrm{Cdc14B}$ by inhibiting the $\mathrm{APC}^{\mathrm{Cdh} 1}$ (Marangos et al. 2007). It remains to be determined how Cdc14B and Emil are developmentally regulated and inactivated to permit oocyte maturation.

\section{Metaphase II Arrest and Release}

A rise in Cdk1/Cyclin B activity is required in mammalian eggs to induce the progression from prophase I to a second arrest at metaphase II, which remains until fertilization (Sagata 1996). The stability of Cdk1/Cyclin B in vertebrates depends on the cytostatic factor 
(CSF), an activity in the cytoplasm of mature Rana pipiens oocytes that was found to induce metaphase arrest when injected into two-cell embryos (Masui and Markert 1971). Breakthrough discoveries in the Xenopus laevis model identified the MOS/MEK1/MAPK/p90 ${ }^{\text {Rsk }}$ and the early mitotic inhibitor 2 (Emi2) pathways as molecular components of the CSF activity and thus key players involved in the metaphase II arrest (Tunquist and Maller 2003; Nishiyama and Kishimoto 2010). In mammals, MOS/ MEK1/MAPK is likely to be required only for maintaining the metaphase II arrest. Mouse oocytes lacking MOS function reach metaphase II arrest but fail to maintain the arrest, as they spontaneously exit meiosis (Colledge et al. 1994; Hashimoto et al. 1994; Verlhac et al. 1996). In contrast, Emi2 plays dual roles in the establishment and maintenance of the second arrest (reviewed in Madgwick and Jones 2007). Both the MOS and Emi2 pathways work together to inhibit the activity of the APC/C and keep Cdk1/Cyclin B active (Madgwick and Jones 2007).

Egg Activation, Release from Metaphase II Arrest, and Entry into Embryogenesis

The oocyte resumes meiosis and becomes competent to begin embryonic development on egg activation. Egg activation is characterized by multiple events including changes in egg coverings to prevent polyspermy, release of the second meiotic arrest and completion of meiosis, posttranscriptional modifications of maternal mRNAs, and cytoskeletal rearrangements (reviewed in Horner and Wolfner 2008). The mammalian egg is activated in a fertilization-dependent manner. The sperm fusion to the egg induces a wave of $\mathrm{Ca}^{2+}$ oscillations within the egg that break the Meta II arrest (Jones 2005; Ducibella and Fissore 2008). However, the molecular mechanisms whereby the sperm $\mathrm{Ca}^{2+}$ signal induces this response have not been fully defined.

It is known that an elevation of $\mathrm{Ca}^{2+}$ at fertilization results in the activation of one downstream effector, calmodulin-dependent protein kinase II (CaMKII) (Tatone et al. 2002;
Markoulaki et al. 2004). In mouse eggs, CaM$\mathrm{KII} \gamma$ is the predominant CaMKII isoform that is essential for egg activation (Backs et al. 2010). CaMKII $\gamma^{-/-}$mice display female-specific sterility because of a failure to decrease MAPK and Cdk1/Cyclin B activities to permit resumption of meiosis (Backs et al. 2010). The direct downstream effectors of CaMKII have not yet been identified. Mechanistically, based on findings in the Xenopus system (Liu and Maller 2005; Rauh et al. 2005; Hansen et al. 2006), and some evidence in mammals (Ducibella and Fissore 2008), CaMKII activation likely leads to the degradation of Emi2. After Emi2 is degraded, the APC/C can target Cyclin B and securin (an inhibitor of the separase protease responsible for release of sister chromatid cohesion) for degradation and in turn inactivate Cdk1/Cyclin B to relieve the meiotic block. In addition to CaMKII, calcineurin (calcium and calmodulin-dependent phosphatase) and protein kinase $\mathrm{C}$ (PKC) appear to be second effector molecules for metaphase II progression in mouse oocytes, although their role is less clear (Jones 2005).

Fertilization induces completion of meiosis and leads to the restart of the mitotic cycle in the embryo, with the first embryonic cell cycle in the one-cell embryo being mostly driven by maternally provided factors (Kubiak et al. 2008). Zygotic transcription becomes prevalent by the second division and presumably subsequent embryonic cell divisions are under zygotic control.

\section{C. elegans}

\section{Regulation of Oocyte Maturation by Sperm} in C. elegans

In C. elegans, signaling from the somatic cells surrounding the oocyte, in this case the sheath cells of the gonad, is crucial in regulating meiotic maturation (Miller et al. 2003). In this organism, however, maturation is controlled by sperm. Hermaphrodite worms make a limited number of sperm during the initial stages of gametogenesis, before transitioning to oocyte production. These sperm are stored in the spermatheca (Fig. 2B) adjacent to the mature 
oocytes. Given the finite number of sperm, forcing oocyte maturation to be dependent on the presence of sperm ensures that oocytes are not wasted and each maturing oocyte becomes fertilized. Sperm signaling promotes oocyte maturation and ovulation, releasing the primary meiotic arrest. Fertilization then leads to egg activation and the completion of meiosis (for review, see Yamamoto et al. 2006).

The major sperm protein (MSP) is the ligand that regulates not only oocyte maturation but also oocyte growth and contraction of the sheath cells (Fig. 2B) (Yamamoto et al. 2006). Originally identified as a cytoskeletal protein needed for motility of these amoeboid sperm, MSP appears to be secreted by a vesicle budding process to form a concentration gradient from the spermatheca (Fig. 2B) (Kosinski et al. 2005). MSP can bind to the ephrin receptor VAB-1 on the oocyte (Miller et al. 2003) and recently has been shown to bind to as yet unidentified receptors on the sheath cells (Fig. 3B) (Govindan et al. 2009).

Delineation of the effects of MSP on maturation and the contributions of the oocyte and sheath cells have been facilitated by the possibility of doing mosaic analysis of mutants, RNAi of candidate players, and by the ability to assay MSP effects by direct injection into the gonad. C. elegans females, which are mutant hermaphrodites that cannot produce sperm, have been used for these injection assays. MSP induces four events that accompany and facilitate ovulation and fertilization: oocyte maturation, microtubule reorganization in the oocyte undergoing maturation, actin-based cytoplasmic streaming that promotes oocyte growth prior to meiotic arrest, and gonadal sheath cell contractions that promote ovulation (Miller et al. 2001; Harris et al. 2006; Govindan et al. 2009).

MSP acts both on the oocyte and the surrounding sheath cells, and recent studies delineated the consequences of MSP binding to sheath cells (Fig. 3B) (Govindan et al. 2006, 2009). These experiments established that binding of MSP causes the activation of $\mathrm{G} \alpha_{\mathrm{s}}(g s a-1)$, which in turn activates adenylate cyclase to elevate cAMP levels. Mutation of the acy-4 adenylate cyclase gene blocks oocyte maturation, and function of the gene is required in the somatic rather than the germline lineage. High overexpression of adenylate cyclase or gain-of-function mutation of $\mathrm{G} \alpha_{\mathrm{s}}$ are capable of triggering meiotic maturation even in the absence of sperm, revealing a direct role for $\mathrm{G} \alpha_{\mathrm{s}}$ signaling and adenylate cyclase in triggering subsequent maturation steps. Activation of $\mathrm{G} \alpha_{\mathrm{s}}$ signaling counteracts inhibitory signals from $\mathrm{G} \alpha_{\mathrm{o} / \mathrm{i}}$ that block oocyte maturation in the absence of MSP. These results imply the presence of a G protein-coupled receptor in sheath cells to which MSP binds, but the receptor has not yet been identified. In summary, $\mathrm{G}_{\mathrm{s}}$-adenylate cyclase mediated signaling functions in the gonadal sheath cells for all characterized MSPdependent meiotic maturation responses.

MSP signaling promotes oocyte activation by blocking inhibition mediated through signaling between the sheath cells and oocytes (Govindan et al. 2009). This signaling requires the gap junction Innexin (invertebrate homolog of connexin) proteins encoded by inx-14 and in $x$-22 expressed in the germline (Fig. 3B) (Whitten and Miller 2007). Mutation of inx22 suppresses the maturation failure of a $g s a-1$ mutant, demonstrating the critical inhibitory role of these gap junctions in oocyte maturation. This mutation, however, does not suppress acy-4 mutants, indicating the existence of other participating pathways.

Although an oocyte receptor for MSP has been identified, the function of MSP signaling within the oocyte in inducing maturation is not clear. Most recent results suggest that it may play a modulatory role in tightly linking oocyte maturation to the presence of sperm. The current data suggest that VAB-1 functions to inhibit meiotic maturation when MSP is absent or limiting and has no essential role in promoting maturation. VAB-1 inhibits meiotic maturation when in, or in transit to, recycling endosomes (Cheng et al. 2008). When MSP is present, the exclusion of VAB-1 from the recycling endosomes requires $\mathrm{G} \alpha_{\mathrm{s}}$ and ACY-4 function in the gonadal sheath cells. Recent data suggest that VAB-1 functions in oocyte meiotic maturation by negatively regulating the DAF18/PTEN pathway (Brisbin et al. 2009). How 
redistribution of MSP to the plasma membrane permits oocyte maturation remains to be elucidated.

Oocyte maturation is accompanied by activation of MAPK within the oocyte, as assayed by phospho-specific antibodies (Miller et al. 2001). Active phosphorylated MPK-1 MAPK is observed in the one to six oocytes most proximal to the spermatheca (see Fig. 2B) (Lee et al. 2007), and this activation requires MSP and $G \alpha_{s}$ signaling in the sheath cells, unless the gap junctions are nonfunctional (Whitten and Miller 2007; Govindan et al. 2009). Meiotic maturation, however, is spatially restricted to the -1 oocyte, albeit it is not known how. Presumably active MAPK causes the onset of meiotic chromosome segregation by the conserved pathways defined in vertebrates, although this remains to be shown directly. Several mutants result in MAPK activation even in the absence of sperm, including the transcription factors CEH-18 (a POU homeodomain transcription factor) and EGRH-1 (an EGR family member) (Rose et al. 1997; Clary and Okkema 2010). These transcription factors act in the soma to repress MAPK activation in the oocyte.

Conserved cell cycle regulators such as POLO kinase, which participates in the Cdk1/ Cyclin B-Cdc25 autoregulatory loop by promoting the phosphorylation and activation of Cdc25 in many systems (Abrieu et al. 1998; Chase et al. 2000; Roshak et al. 2000; Karaiskou et al. 2004), and Cdk1 also function as positive regulators of meiotic maturation in C. elegans. Disruption of POLO-like kinase 1 (PLK-1) or NCC-1/Cdk1, via RNAi, result in defects in nuclear envelope breakdown prior to ovulation (Boxem et al. 1999; Chase et al. 2000). Wormspecific proteins such as the zinc finger domain-containing proteins OMA- 1 and OMA-2 also promote meiotic maturation upstream of Cdk1 (Detwiler et al. 2001).

\section{Control of the Transition from Oocyte to Zygote in C. elegans}

Release of meiotic arrest in the oocyte by fertilization also ensures proper control of the restart of the mitotic cell cycle in the zygote. During embryogenesis there is a handoff from maternal to zygotic control of development, but the timing of this transition varies markedly between animals. In C. elegans, the mechanisms to terminate maternal control begin at oocyte maturation. The MBK-2 kinase, a member of the dual-specificity tyrosine-regulated family (DYRKs), phosphorylates maternal proteins to contribute to the oocyte-zygote transition (Stitzel et al. 2006). For example, phosphorylation of the katanin protein MEI-1 by MBK-2 leads to its degradation, preventing it from severing microtubules after completion of meiosis and thereby possibly disrupting zygotic development. Other proteins phosphorylated by MBK-2 include MEX-2 and MEX-6. MBK-2 phosphorylation of these two proteins primes them for phosphorylation by POLO kinase, permitting them to act to establish anteriorposterior polarity in the early zygote. Phosphorylation of the OMA-1 and OMA-2 proteins by MBK-2 converts their function from that in oocyte maturation to the ability to sequester TAF-4 and block transcription in the germline precursor cells in the embryo (Guven-Ozkan et al. 2008).

The activation of MBK-2 is tightly regulated during oocyte development. Cdk1 phosphorylates MBK-2 during oocyte maturation, making it capable of phosphorylating MEI-1 (Cheng et al. 2009). The mechanism of this activation is unknown, but may involve inactivation or release of an inhibitor. Activity of MBK-2 is blocked, however, until anaphase I by its retention at the oocyte cortex by the EGG-3 protein (Stitzel et al. 2007). In addition, it is bound at the cortex by the EGG-4 and EGG-5 proteins (Cheng et al. 2009; Parry et al. 2009). These proteins have homology to tyrosine phosphatases but appear to lack active catalytic sites. They bind to MBK-2 and have been shown in vitro to block its kinase activity. Ablation of egg-4 and egg- 5 by RNAi leads to premature phosphorylation of the MEI-1 substrate in oocytes, consistent with EGG-4 and EGG-5 playing crucial roles to restrict MBK-2 kinase activity in vivo. If these genes are ablated or mutated meiosis is abnormal, polar bodies do not form, the eggshell is not properly produced, 
and polyspermy can occur. The APC, which is active at the metaphase I/anaphase I transition, releases the complex from the cortex, resulting in MBK-2 activation. The APC targets EGG-3 for degradation and possibly EGG-4 and EGG-5 as well.

\section{DROSOPHILA}

\section{Prophase I Arrest}

The Drosophila oocyte, which is differentiated from a 16-cell cyst, enters the early events of prophase $\mathrm{I}$ in region $2 \mathrm{~A}$ in the germarium, and by stage 5 of egg chamber development arrests for the first time in the equivalent of diplotene, with the chromosomes compacted into a karyosome (Fig. 2C) (Page and Hawley 2001; Resnick et al. 2009). The other 15 nurse cell sisters instead enter the endocycle (DNA replication without mitosis) to become highly polyploid (Hong et al. 2003). In Drosophila, the $\mathrm{p} 21 \mathrm{CIP} / \mathrm{p} 27 \mathrm{KIP} 1 / \mathrm{p} 57 \mathrm{KIP} 2-$ like Cdk inhibitor, Dacapo (DAP), is required within the oocyte to inhibit the kinase activity of Cdk2/ Cyclin E and thus prevent DNA replication or entry into the endocycle (Hong et al. 2003).

Contrary to mammals and C. elegans, in Drosophila it has not been established whether gap junction-mediated communication between the somatic follicle cells and the oocyte is required to maintain prophase I meiotic arrest. Interestingly, the proteins that compose the gap junction channels, innexins (Inx), are widely expressed during Drosophila oogenesis (Stebbings et al. 2002). In fact, in vitro injections with antisera against Inx2 (a gap junction protein between oocyte and follicle cells) into stage 10 follicle-enclosed oocytes significantly affected development past stage 10 by blocking follicle cell differentiation, nurse cell regression, and oocyte growth (Bohrmann and Zimmermann 2008). Those oocytes that bypassed the developmental arrest showed defects in chorion formation; however, meiosis was not analyzed in these oocytes (Bohrmann and Zimmermann 2008). To date, no roles for the Drosophila cAMP transduction pathway during meiosis have been established.
Cross talk between the oocyte and the surrounding follicle cells is required for follicle cell fate determination and patterning of the egg and embryo (Ray and Schupbach 1996; Gonzalez-Reyes et al. 1997). Thus, it is possible that this bidirectional communication also regulates meiotic events in the oocyte. In addition, there is signaling between meiotic progression and developmental patterning. Mutants in which meiotic double-strand breaks are not repaired have dorsal/ventral patterning defects in the developing oocyte. These unrepaired breaks are sensed and lead to a failure to translate Gurken, the ligand secreted from the oocyte that directs determination of the adjacent follicle cells (Ghabrial and Schupbach 1999; Abdu et al. 2002).

\section{Meiotic Maturation}

The Drosophila oocyte undergoes meiotic maturation at stage 13 of oogenesis (Xiang et al. 2007; Von Stetina et al. 2008). Consistent with a potential requirement of active Cdk1/Cyclin $\mathrm{B}$ in Drosophila during this process, temperature-sensitive mutations in $c d k 1$ delay the timing of meiotic maturation (Fig. 4) (Von Stetina et al. 2008). In addition, mutants of twine ( $t w e$ ), the meiotic homolog of the phosphatase Cdc25 (Alphey et al. 1992; Courtot et al. 1992; White-Cooper et al. 1993), also are delayed in the disassembly of the nuclear envelope (Xiang et al. 2007; Von Stetina et al. 2008). Recent discoveries with mutations affecting the developmental timing of maturation identified new regulators of Twine and Polo, confirming the link between maturation and Cdk1/Cyclin B activity.

The Drosophila $\alpha$-endosulfine homolog, endos, which encodes a conserved phosphoprotein, regulates all aspects of meiotic maturation including the timing of nuclear envelope breakdown (NEB) (Von Stetina et al. 2008). endos mutant oocytes display a severe delay in NEB, spindle formation and chromosome congression defects very similar to twe mutants. The Endos protein likely exerts its control on meiotic maturation by controlling Cdk1/Cyclin B activity, as it controls the protein stability of 


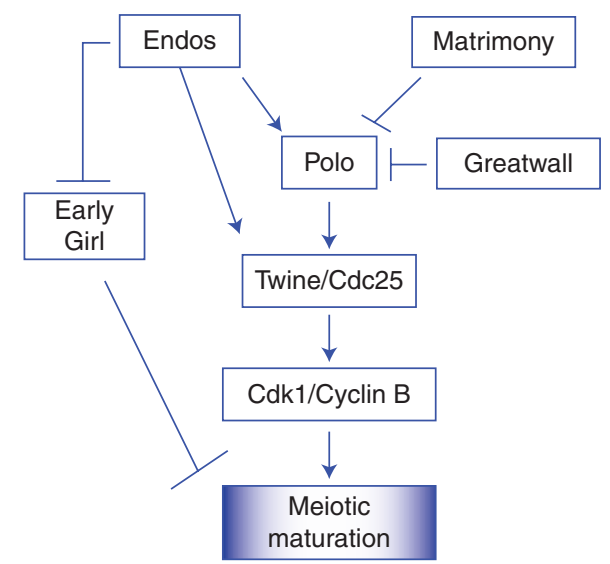

Figure 4. Regulatory genes affecting meiotic maturation in Drosophila. Evidence in Drosophila suggests that high levels of Cdk1/Cyclin B activity are required for meiotic maturation. The Polo kinase phosphorylates and activates the phosphatase Twine/Cdc25, which in turn phosphorylates and activates Cdk1. Before nuclear envelope breakdown (NEB), Matrimony sets the timing of meiotic maturation by inhibiting Polo activity. Endos positively regulates the timing of meiotic maturation by regulating the levels of Polo and Twine/Cdc25, which are required to promote Cdk1/Cyclin B activation. Independently, Endos inhibits the predicted E3 ubiquitin ligase Early Girl. The Greatwall kinase also inhibits Polo.

Twine/Cdc25 and Polo (Fig. 4) (Von Stetina et al. 2008). Although an in vitro reduction of Cdk1/Cyclin B kinase activity toward its substrate histone 1 (H1) was not observed in endos mutant oocytes, endos might affect the activity of Cdk1/Cyclin B toward other key substrates other than $\mathrm{H} 1$ in vivo (Von Stetina et al. 2008). Consistent with this, in endos mutants there is a marked reduction in the phosphorylation of mitotic protein monoclonal 2 (MPM2) conserved epitopes (Davis et al. 1983), normally phosphorylated by both Polo and Cdk1/Cyclin B in Drosophila (Logarinho and Sunkel 1998; Von Stetina et al. 2008). Finally, Endos physically interacts with a predicted E3 ubiquitin ligase encoded by early girl (elgi) (Von Stetina et al. 2008), which is also required for the timing of oocyte maturation. Contrary to endos mutants, some oocytes from mutants of elgi undergo premature nuclear envelope breakdown
(Von Stetina et al. 2008). How Endos controls meiosis via Elgi is currently unknown.

Whereas endos is needed for normal levels of Polo in oocytes, premature activation of Polo prior to maturation is prevented by the protein encoded by Matrimony (Mtrm), which physically interacts with Polo (Fig. 4) (Xiang et al. 2007). Mtrm/ + heterozygous females undergo NEB precociously, and this phenotype can be fully suppressed by reducing the dose of polo (Xiang et al. 2007). The current model predicts that an excess of Mtrm inhibits Polo proteins prior to the onset of NEB (Xiang et al. 2007). On meiotic maturation at stage 13, Polo proteins exceed the available amounts of inhibitory Mtrm proteins and activate Twine/ Cdc25, which in turn leads to the activation of Cdk1/Cyclin B and NEB. Independent results also show that the conserved Greatwall kinase (Gwl), discovered in flies (Yu et al. 2004), antagonizes Polo activity during meiosis (Archambault et al. 2007). Consistent with this role, homozygosity of the Scott of the Antarctic (Scant) mutation in the gwl gene, which results in kinase hyperactivity of Gwl, reduces Polo levels and suppresses the Mtrm/ + meiotic phenotypes (Archambault et al. 2007).

Currently, the extrinsic signal(s) that triggers oocyte meiotic maturation in Drosophila is unknown. Prostaglandin hormones or the steroid hormone ecdysone could serve as potential stimulatory signals. Drosophila cyclooxygenase (COX), one of the enzymes responsible for synthesis of prostaglandins, promotes early ovarian follicle maturation (Tootle and Spradling 2008). Ecdysone signaling is also required for progression of oogenesis and egg chamber maturation during mid-oogenesis (Buszczak et al. 1999). Because the follicles in mutants affecting either signaling pathways do not reach stage 13 (when meiotic maturation takes place), it is not known whether prostaglandins or ecdysone are required for meiotic maturation in flies.

\section{Metaphase I Arrest and Release of Arrest}

On meiotic maturation, the Drosophila oocyte arrests for a second time at metaphase I at stage 14 (Figs. 1, 2C) (King 1970). During this arrest 
the exchange and nonexchange chromosomes cluster into a "lemon-shaped" DNA structure (Hughes et al. 2009). The metaphase I arrest is maintained by (1) the tension on the kinetochores resulting from the early exchange events between the homologs (chiasmata) (McKim et al. 1993; Jang et al. 1995), and (2) heterochromatin pairings between the nonexchange chromosomes (achiasmate) and their congression to the spindle midzone via heterochromatin threads (Hawley et al. 1992; Dernburg et al. 1996; Hughes et al. 2009).

Some evidence points to regulation of Cdk1/Cyclin B activity as being critical for maintenance of the secondary meiotic arrest in Drosophila. Degradation of Cyclin B is required for release of the metaphase I arrest. Oocytes that express nondegradable Cyclin B and thus cannot inactivate Cdk1/Cyclin B, do not resume meiosis (Swan and Schupbach 2007). There is an oocyte-specific form of the APC/C, activated by the Cortex Cdc20 family member, needed solely for the completion of meiosis in the oocyte (Pesin and Orr-Weaver 2007; Swan and Schupbach 2007). Both APC/ $\mathrm{C}^{\mathrm{CORT}}$ and $\mathrm{APC} / \mathrm{C}^{\mathrm{FZY}(\mathrm{Cdc} 20)}$ forms are present in oocytes and appear redundant for the metaphase I-to-anaphase I transition, whereas APC/ $\mathrm{C}^{\text {CORT }}$ is essential for the metaphase II-toanaphase II transition (Pesin and Orr-Weaver 2007; Swan and Schupbach 2007).

Several genes involved in controlling different aspects of meiosis in the oocyte also fail to undergo metaphase I arrest when mutated. For example, in addition to the delay in the onset of meiotic maturation, endos and twe mutants fail to arrest at metaphase I (Xiang et al. 2007; Von Stetina et al. 2008). Oocytes with a meiotic-specific mutation in the $g w l$ gene $\left(g w l^{S r 18}\right)$, display scattered chromosomes and do not align properly on the metaphase plate because of premature loss of (or failure to establish) arm cohesion (Archambault et al. 2007). Mutants of ald, the Drosophila homolog of the conserved checkpoint component mps1, bypass the metaphase I arrest and enter anaphase I precociously (Gilliland et al. 2007). The defective spindle assembly checkpoint the (SAC) response in ald mutants is because of loss of sister-chromatin cohesion along the euchromatic arms and leads to high incidence of chromosome nondisjunction. Interestingly, the SAC is dispensable for cytostastic factor (CSF) arrest in mammals (Tsurumi et al. 2004).

Despite the strong requirement for the MAPK pathway for many meiotic events in vertebrates and C. elegans, MOS signaling is not essential in Drosophila (Ivanovska et al. 2004). Drosophila MOS (DMOS) has CSF activity when injected into two-cell Xenopus embryos and is required for MAPK phosphorylation in the Drosophila ovary. dmos mutant oocytes, nevertheless, have a normal metaphase I arrest. MAPK phosphorylation, however, is not completely eliminated in these mutants. Therefore, we cannot rule out a role of MOS in Drosophila meiosis or the presence of a redundant MAPKKK.

\section{Egg Activation/Entry into Embryogenesis}

Egg activation in Drosophila occurs independently of fertilization (Table 1) (Horner and Wolfner 2008). Instead, mechanical stimulation via passage through the oviduct and rehydration trigger egg activation and completion of meiosis (Mahowald et al. 1983). Recent studies point to a link between $\mathrm{Ca}^{2+}$-dependent signaling and the resumption of meiosis. Oocytes carrying mutations in Drosophila Calcipressin, sarah (sra), an inhibitor of the $\mathrm{Ca}^{2+} /$ calmodulin-dependent phosphatase calcineurin, arrest at anaphase I and show high levels of Cyclin B (Horner et al. 2006; Takeo et al. 2006, 2010). These phenotypes suggest that inactivation of Cdk1/Cyclin B does not occur in sra mutants because the APC/C is not active (Horner and Wolfner 2008). No roles for CamkII in Drosophila egg activation have been established yet.

There are specialized regulators required for the onset of mitotic divisions in the Drosophila embryo following the completion of meiosis. The PAN GU (PNG) kinase complex, composed of the PNG kinase subunit and two activating subunits PLU and GNU, is necessary for the onset of mitotic activity following meiosis (Lee et al. 2003). This is first manifested in a requirement for PNG activity in the chromosome condensation that follows a transient 
interphase for the meiotic products in the egg after the completion of both meiotic divisions. In the absence of PNG function the meiotic products remain decondensed and inappropriately undergo DNA replication, and the male and female pronuclei do not undergo mitosis. This failure to restart mitosis following meiosis in png mutants is caused by reduced Cyclin B levels, as PNG promotes translation of Cyclin $\mathrm{B}$ at egg activation (Lee et al. 2001; Vardy and Orr-Weaver 2007a). PNG also is needed for the translation of Smaug (SMG), which later in embryogenesis facilitates the transition from maternal to zygotic control by promoting degradation of maternal mRNAs (Tadros et al. 2007). The nuclear protein YA is activated after egg activation and necessary for the first mitotic division (Sackton et al. 2009).

\section{CONCLUDING REMARKS}

Relationship between Reproductive Strategy and the Regulation of Oocyte Meiosis

Comparison of the control mechanisms for oocyte maturation, meiotic arrest, and egg activation between mammals, C. elegans, and Drosophila highlights evolutionary conservation in general strategies and molecular regulators while illustrating unique adaptations for specific reproductive goals (Table 1). Thus, distinct regulatory steps between these organisms provide informative insights into their reproductive success.

The self-fertilizing hermaphrodite C. elegans differs from most animals in having a limited number of sperm. Sperm are produced in the germline in the last larval stage and, during the adult lifespan, solely oocytes are produced. The critical role of sperm signaling via MSP to control oocyte maturation and egg activation puts the sperm in control. Making oocyte maturation dependent on the presence of sperm helps guarantee that each sperm will be able to fertilize an egg thereby ensuring optimal usage of the limiting gamete.

In contrast, in Drosophila egg activation and release of the secondary meiotic arrest are independent of sperm and fertilization. Solely movement of the oocyte into the uterus is sufficient for the completion of meiosis, although sperm proteins do stimulate egg laying in the female (Avila et al. 2010). Because some Drosophila species such as D. mercatorum are capable of parthenogenic development (Eisman and Kaufman 2007), we speculate that the independence of egg activation from sperm signals is a remnant of Drosophila's capability to reproduce asexually. Although most Drosophila species have acquired dependence on fertilization for embryogenesis, they retain independence for egg activation. Given the investment in egg production in a Drosophila female, it is puzzling that eggs can be activated and laid in the absence of fertilization. Drosophila females may respond more to the nutritional state of their environment than to the presence of sperm. An important question will be to define the developmental cues regulating oocyte maturation in Drosophila and to delineate how these may be linked to environmental factors such as nutritional status and mating.

In mammals, a finite number of oocytes are produced during fetal development, differentiating to the primary arrest point. Although during each estrus cycle an oocyte undergoes maturation, no further oocytes are produced postnatally. Consequently, each oocyte is a precious commodity, explaining the precise regulation of oocyte maturation. Hormonal control links oocyte maturation with preparation of the uterus for potential implantation. The essential role of the somatic support cells in triggering oocyte maturation may serve as a control to ensure that the oocyte has grown and developed sufficiently prior to resumption of meiosis. This may also guarantee that the oocyte is ready to be delivered to the oviduct by the time of ovulation. Linking the completion of meiosis to fertilization provides a mechanism that permits development of the oocyte with a diploid genomic content while guaranteeing that haploid male and female pronuclei are present simultaneously to allow for syngamy and the onset of zygotic divisions. The dependency of completion of meiosis on fertilization also provides an additional mechanism to prevent parthenogenesis. 


\section{The Role of Cell-Cell Communication and Second Messengers}

The recent developments in mouse and C. elegans define striking parallels in the regulation of oocyte maturation by somatic support cells. In mammals high cAMP in the oocyte maintains the prophase I arrest, but in both mammals and $C$. elegans elevation of cAMP in surrounding support cells in response to $\mathrm{LH}$ and MSP, respectively, triggers maturation. In $C$. elegans it will be informative to know whether the increase in Protein Kinase A resulting from cAMP acts in the sheath cell or the oocyte, as well as what molecules transit through the gap junctions to overcome the inhibition of maturation. Identification and regulation of the receptor in the sheath cell responding to MSP signaling also will be an important next step. A fascinating parallel between the mammalian and C. elegans systems is that maturation in mouse is associated with inactivation of gap junctions between the oocyte and the surrounding follicle cells, as in C. elegans. Given these shared mechanisms, it will be interesting to determine whether Drosophila follicle cells contribute to oocyte maturation and whether the innexin gap junctions between the oocyte and follicle cells inhibit maturation during the primary arrest. Although Drosophila mutations in protein kinase A are female sterile (Lane and Kalderon 1995), to date it has not been possible to address the function of protein kinase A in oocyte maturation because the mutants arrest too early in oogenesis.

\section{Coordination between Developmental and Cell Cycle Control in the Oocyte}

In metazoan oocytes, it is crucial that progression through meiosis be linked properly to differentiation, but recent discoveries show that meiotic progression can also influence development. Hormonal control of oocyte maturation in mammals and Xenopus illustrates a mechanism by which developmental input impinges on the meiotic cell cycle. In Drosophila, the onset of maturation coincides with a distinct stage of egg chamber differentiation, but the developmental cues accompanying this have yet to be unraveled.

The recent advances in C. elegans and Drosophila show that a reciprocal relationship exists between developmental and meiotic regulation, uncovered by examples in which cell cycle events and progression affect developmental control. In the worm, activation of Cyclin B/Cdk1 kinase at oocyte maturation leads to phosphorylation of MBK-2, making it active to phosphorylate its substrates once it is released from the cortex. Failure to repair double-strand breaks in Drosophila meiosis causes defects in dorsal-ventral patterning of the oocyte because of a defect in translation of Gurken. In addition, proper regulation of Polo levels and activity by Endos and Mtrm are necessary for the timing of meiosis I. It is interesting that in both C. elegans and Drosophila specific kinases act uniquely to control the oocyte to zygote transition: in C. elegans, MBK-2 alters the activity or level of maternal proteins and, in Drosophila, PNG promotes translation to start the embryonic mitotic divisions and later degrade maternal mRNAs.

Much remains to be uncovered to understand fully the regulatory mechanisms coordinating oocyte meiosis and development. The recent discoveries in mouse, C. elegans, and Drosophila have identified new proteins essential to link these processes as well as illustrated the roles played by conserved signal transduction pathways and second messengers. The parallels between these model organisms lead to powerful synergy in the analysis and discovery of these regulatory mechanisms.

\section{ACKNOWLEDGMENTS}

We would like to thank Tom DiCesare for preparing Figures 1-3, David Greenstein for assistance with Figure 3B, David Greenstein, Andreas Hochwagen, Cintia Hongay, and Laurinda Jaffe for many helpful comments on the manuscript, and Laurinda Jaffe and Takeo Kishimoto for providing manuscripts in press. T.L.O.-W. is an American Cancer Society Research Professor and support for the preparation of this article was provided also by NIH grant GM39341. 
J.R. Von Stetina and T.L. Orr-Weaver

\section{REFERENCES}

Abdu U, Brodsky M, Schupbach T. 2002. Activation of a meiotic checkpoint during Drosophila oogenesis regulates the translation of Gurken through Chk2/Mnk. Curr Biol 12: 1645-1651.

Abrieu A, Brassac T, Galas S, Fisher D, Labbe JC, Doree M. 1998. The Polo-like kinase Plx1 is a component of the MPF amplification loop at the $\mathrm{G}_{2} / \mathrm{M}$-phase transition of the cell cycle in Xenopus eggs. J Cell Sci 111: 17511757.

Alphey L, Jimenez J, White-Cooper H, Dawson I, Nurse P, Glover DM. 1992. twine, a cdc25 homolog that functions in the male and female germline of Drosophila. Cell 69: 977-988.

Archambault V, Zhao X, White-Cooper H, Carpenter AT, Glover DM. 2007. Mutations in Drosophila Greatwall/ Scant reveal its roles in mitosis and meiosis and interdependence with Polo kinase. PLoS Genet 3: e200.

Avila FW, Ravi Ram K, Bloch Qazi MC, Wolfner MF. 2010. Sex peptide is required for the efficient release of stored sperm in mated Drosophila females. Genetics 186: $595-$ 600.

Backs J, Stein P, Backs T, Duncan FE, Grueter CE, McAnally J, Qi X, Schultz RM, Olson EN. 2010. The $\gamma$ isoform of CaM kinase II controls mouse egg activation by regulating cell cycle resumption. Proc Natl Acad Sci 107: 81-86.

Bohrmann J, Zimmermann J. 2008. Gap junctions in the ovary of Drosophila melanogaster: Localization of innexins 1, 2, 3 and 4 and evidence for intercellular communication via innexin-2 containing channels. BMC Dev Biol 8: 111 .

Boxem M, Srinivasan DG, van den Heuvel S. 1999. The Caenorhabditis elegans gene $n c c-1$ encodes a cdc2-related kinase required for $\mathrm{M}$ phase in meiotic and mitotic cell divisions, but not for S phase. Development 126: 2227 2239.

Brisbin S, Liu J, Boudreau J, Peng J, Evangelista M, ChinSang I. 2009. A role for C. elegans Eph RTK signaling in PTEN regulation. Dev Cell 17: 459-469.

Buszczak M, Freeman MR, Carlson JR, Bender M, Cooley L, Segraves WA. 1999. Ecdysone response genes govern egg chamber development during mid-oogenesis in Drosophila. Development 126: 4581-4589.

Chase D, Serafinas C, Ashcroft N, Kosinski M, Longo D, Ferris DK, Golden A. 2000. The Polo-like kinase PLK-1 is required for nuclear envelope breakdown and the completion of meiosis in Caenorhabditis elegans. Genesis 26: 26-41.

Cheng H, Govindan JA, Greenstein D. 2008. Regulated trafficking of the MSP/Eph receptor during oocyte meiotic maturation in C. elegans. Curr Biol 18: 705-714.

Cheng KC, Klancer R, Singson A, Seydoux G. 2009. Regulation of MBK-2/DYRK by CDK-1 and the pseudophosphatases EGG-4 and EGG-5 during the oocyte-toembryo transition. Cell 139: 560-572.

Clary LM, Okkema PG. 2010. The EGR family gene egrh-1 functions non-autonomously in the control of oocyte meiotic maturation and ovulation in C. elegans. Development 137: 3129-3137.
Colledge WH, Carlton MB, Udy GB, Evans MJ. 1994. Disruption of c-mos causes parthenogenetic development of unfertilized mouse eggs. Nature 370: 65-68.

Conti M, Andersen CB, Richard F, Mehats C, Chun SY, Horner K, Jin C, Tsafriri A. 2002. Role of cyclic nucleotide signaling in oocyte maturation. Mol Cell Endocrinol 187: 153-159.

Conti M, Hsieh M, Park JY, Su YQ. 2006. Role of the epidermal growth factor network in ovarian follicles. Mol Endocrinol 20: 715-723.

Courtot C, Fankhauser C, Simanis V, Lehner CF. 1992. The Drosophila cde25 homolog twine is required for meiosis. Development 116: 405-416.

Davis FM, Tsao TY, Fowler SK, Rao PN. 1983. Monoclonal antibodies to mitotic cells. Proc Natl Acad Sci 80: 2926-2930.

Dernburg AF, Sedat JW, Hawley RS. 1996. Direct evidence of a role for heterochromatin in meiotic chromosome segregation. Cell 86: 135-146.

Detwiler MR, Reuben M, Li X, Rogers E, Lin R. 2001. Two zinc finger proteins, OMA-1 and OMA-2, are redundantly required for oocyte maturation in C. elegans. Dev Cell 1: 187-199.

DiLuigi A, Weitzman VN, Pace MC, Siano LJ, Maier D, Mehlmann LM. 2008. Meiotic arrest in human oocytes is maintained by a $\mathrm{G}_{\mathrm{s}}$ signaling pathway. Biol Reprod 78: $667-672$.

Ducibella T, Fissore R. 2008. The roles of $\mathrm{Ca}^{2+}$, downstream protein kinases, and oscillatory signaling in regulating fertilization and the activation of development. Dev Biol 315: 257-279.

Edry I, Sela-Abramovich S, Dekel N. 2006. Meiotic arrest of oocytes depends on cell-to-cell communication in the ovarian follicle. Mol Cell Endocrinol 252: 102-106.

Eisman R, Kaufman TC. 2007. Cytological investigation of the mechanism of parthenogenesis in Drosophila mercatorum. Fly (Austin) 1: 317-329.

Freudzon L, Norris RP, Hand AR, Tanaka S, Saeki Y, Jones TL, Rasenick MM, Berlot CH, Mehlmann LM, Jaffe LA. 2005. Regulation of meiotic prophase arrest in mouse oocytes by GPR3, a constitutive activator of the $\mathrm{G}_{\mathrm{s}} \mathrm{G}$ protein. J Cell Biol 171: 255-265.

Ghabrial A, Schupbach T. 1999. Activation of a meiotic checkpoint regulates translation of Gurken during Drosophila oogenesis. Nat Cell Biol 1: 354-357.

Gilliland WD, Hughes SE, Cotitta JL, Takeo S, Xiang Y, Hawley RS. 2007. The multiple roles of Mps1 in Drosophila female meiosis. PLoS Genet 3: e113.

Gonzalez-Reyes A, Elliott H, St Johnston D. 1997. Oocyte determination and the origin of polarity in Drosophila: The role of the spindle genes. Development 124: 49274937.

Govindan JA, Cheng H, Harris JE, Greenstein D. 2006. G $\alpha_{\mathrm{o} / \mathrm{i}}$ and $\mathrm{G} \alpha_{\mathrm{s}}$ signaling function in parallel with the MSP/Eph receptor to control meiotic diapause in C. elegans. Curr Biol 16: 1257-1268.

Govindan JA, Nadarajan S, Kim S, Starich TA, Greenstein D. 2009. Somatic cAMP signaling regulates MSP-dependent oocyte growth and meiotic maturation in C. elegans. Development 136: 2211-2221. 
Guven-Ozkan T, Nishi Y, Robertson SM, Lin R. 2008. Global transcriptional repression in C. elegans germline precursors by regulated sequestration of TAF-4. Cell 135: 149-160.

Hambleton R, Krall J, Tikishvili E, Honeggar M, Ahmad F, Manganiello VC, Movsesian MA. 2005. Isoforms of cyclic nucleotide phosphodiesterase PDE3 and their contribution to cAMP hydrolytic activity in subcellular fractions of human myocardium. J Biol Chem 280: 39168-39174.

Han SJ, Chen R, Paronetto MP, Conti M. 2005. Wee1B is an oocyte-specific kinase involved in the control of meiotic arrest in the mouse. Curr Biol 15: 1670-1676.

Hansen DV, Tung JJ, Jackson PK. 2006. CaMKII and Pololike kinase 1 sequentially phosphorylate the cytostatic factor Emi2/XErp1 to trigger its destruction and meiotic exit. Proc Natl Acad Sci 103: 608-613.

Harris JE, Govindan JA, Yamamoto I, Schwartz J, Kaverina I, Greenstein D. 2006. Major sperm protein signaling promotes oocyte microtubule reorganization prior to fertilization in Caenorhabditis elegans. Dev Biol 299: 105-121.

Hashimoto N, Watanabe N, Furuta Y, Tamemoto H, Sagata N, Yokoyama M, Okazaki K, Nagayoshi M, Takeda N, Ikawa Y, et al. 1994. Parthenogenetic activation of oocytes in c-mos-deficient mice. Nature 370: 68-71.

Hawley RS, Irick H, Zitron AE, Haddox DA, Lohe A, New C, Whitley MD, Arbel T, Jang J, McKim K, et al. 1992. There are two mechanisms of achiasmate segregation in Drosophila females, one of which requires heterochromatic homology. Dev Genet 13: 440-467.

Hinckley M, Vaccari S, Horner K, Chen R, Conti M. 2005. The G-protein-coupled receptors GPR3 and GPR12 are involved in cAMP signaling and maintenance of meiotic arrest in rodent oocytes. Dev Biol 287: 249-261.

Hong A, Lee-Kong S, Iida T, Sugimura I, Lilly MA. 2003. The p27cip/kip ortholog dacapo maintains the Drosophila oocyte in prophase of meiosis I. Development 130: $1235-1242$.

Horner VL, Wolfner MF. 2008. Transitioning from egg to embryo: Triggers and mechanisms of egg activation. Dev Dyn 237: 527-544.

Horner K, Livera G, Hinckley M, Trinh K, Storm D, Conti M. 2003. Rodent oocytes express an active adenylyl cyclase required for meiotic arrest. Dev Biol 258: 385396.

Horner VL, Czank A, Jang JK, Singh N, Williams BC, Puro J, Kubli E, Hanes SD, McKim KS, Wolfner MF, et al. 2006. The Drosophila calcipressin sarah is required for several aspects of egg activation. Curr Biol 16: 1441-1446.

Hughes SE, Gilliland WD, Cotitta JL, Takeo S, Collins KA, Hawley RS. 2009. Heterochromatic threads connect oscillating chromosomes during prometaphase I in Drosophila oocytes. PLoS Genet 5: e1000348.

Hunt PA, Hassold TJ. 2008. Human female meiosis: What makes a good egg go bad? Trends Genet 24: 86-93.

Ivanovska I, Lee E, Kwan KM, Fenger DD, Orr-Weaver TL. 2004. The Drosophila MOS ortholog is not essential for meiosis. Curr Biol 14: 75-80.

Jaffe LA, Norris RP. 2010. Initiation of the meiotic prophase-to-metaphase transition in mammalian oocytes. In Oogenesis: The universal process (ed. Verlhac M-H, Villenuve A), pp. 181-198. Wiley, New York.
Jang JK, Messina L, Erdman MB, Arbel T, Hawley RS. 1995. Induction of metaphase arrest in Drosophila oocytes by chiasma-based kinetochore tension. Science 268: $1917-$ 1919.

Jones KT. 2004. Turning it on and off: M-phase promoting factor during meiotic maturation and fertilization. $\mathrm{Mol}$ Hum Reprod 10: 1-5.

Jones KT. 2005. Mammalian egg activation: From $\mathrm{Ca}^{2+}$ spiking to cell cycle progression. Reproduction 130: 813-823.

Kalinowski RR, Berlot CH, Jones TL, Ross LF, Jaffe LA, Mehlmann LM. 2004. Maintenance of meiotic prophase arrest in vertebrate oocytes by a $G_{s}$ protein-mediated pathway. Dev Biol 267: 1-13.

Karaiskou A, Lepretre AC, Pahlavan G, Du Pasquier D, Ozon R, Jessus C. 2004. Polo-like kinase confers MPF autoamplification competence to growing Xenopus oocytes. Development 131: 1543-1552.

King RC. 1970. The meiotic behavior of the Drosophila oocyte. Int Rev Cytol 28: 125-168.

Kishimoto T. 2003. Cell-cycle control during meiotic maturation. Curr Opin Cell Biol 15: 654-663.

Kosinski M, McDonald K, Schwartz J, Yamamoto I, Greenstein D. 2005. C. elegans sperm bud vesicles to deliver a meiotic maturation signal to distant oocytes. Development 132: 3357-3369.

Kovo M, Kandli-Cohen M, Ben-Haim M, Galiani D, Carr DW, Dekel N. 2006. An active protein kinase A (PKA) is involved in meiotic arrest of rat growing oocytes. Reproduction 132: 33-43.

Kubiak JZ, Ciemerych MA, Hupalowska A, Sikora-Polaczek M, Polanski Z. 2008. On the transition from the meiotic to mitotic cell cycle during early mouse development. Int J Dev Biol 52: 201-217.

Kuwabara PE. 2003. The multifaceted C. elegans major sperm protein: An ephrin signaling antagonist in oocyte maturation. Genes Dev 17: 155-161.

Lane ME, Kalderon D. 1995. Localization and functions of protein kinase A during Drosophila oogenesis. Mech Dev 49: 191-200.

Lee LA, Elfring LK, Bosco G, Orr-Weaver TL. 2001. A genetic screen for suppressors and enhancers of the Drosophila PAN GU cell cycle kinase identifies cyclin B as a target. Genetics 158: 1545-1556.

Lee LA, Van Hoewyk D, Orr-Weaver TL. 2003. The Drosophila cell cycle kinase PAN GU forms an active complex with PLUTONIUM and GNU to regulate embryonic divisions. Genes Dev 17: 2979-2991.

Lee MH, Ohmachi M, Arur S, Nayak S, Francis R, Church D, Lambie E, Schedl T. 2007. Multiple functions and dynamic activation of MPK-1 extracellular signalregulated kinase signaling in Caenorhabditis elegans germline development. Genetics 177: 2039-2062.

Lincoln AJ, Wickramasinghe D, Stein P, Schultz RM, Palko ME, De Miguel MP, Tessarollo L, Donovan PJ. 2002. $\mathrm{Cdc} 25 \mathrm{~b}$ phosphatase is required for resumption of meiosis during oocyte maturation. Nat Genet 30: 446-449.

Liu J, Maller JL. 2005. Calcium elevation at fertilization coordinates phosphorylation of XErp1/Emi2 by Plx1 and CaMK II to release metaphase arrest by cytostatic factor. Curr Biol 15: 1458-1468. 
J.R. Von Stetina and T.L. Orr-Weaver

Logarinho E, Sunkel CE. 1998. The Drosophila POLO kinase localises to multiple compartments of the mitotic apparatus and is required for the phosphorylation of MPM2 reactive epitopes. J Cell Sci 111: 2897-2909.

Madgwick S, Jones KT. 2007. How eggs arrest at metaphase II: MPF stabilisation plus APC/C inhibition equals cytostatic factor. Cell Div 2: 4.

Mahowald AP, Goralski TJ, Caulton JH. 1983. In vitro activation of Drosophila eggs. Dev Biol 98: 437-445.

Marangos P, Verschuren EW, Chen R, Jackson PK, Carroll J. 2007. Prophase I arrest and progression to metaphase I in mouse oocytes are controlled by Emi1-dependent regulation of APC(Cdh1). J Cell Biol 176: 65-75.

Markoulaki S, Matson S, Ducibella T. 2004. Fertilization stimulates long-lasting oscillations of CaMKII activity in mouse eggs. Dev Biol 272: 15-25.

Masui Y, Markert CL. 1971. Cytoplasmic control of nuclear behavior during meiotic maturation of frog oocytes. $J$ Exp Zool 177: 129-145.

Matzuk MM, Lamb DJ. 2002. Genetic dissection of mammalian fertility pathways. Nat Cell Biol 4: s41-49.

McKim KS, Jang JK, Theurkauf WE, Hawley RS. 1993. Mechanical basis of meiotic metaphase arrest. Nature 362: $364-366$.

Mehlmann LM. 2005a. Oocyte-specific expression of Gpr3 is required for the maintenance of meiotic arrest in mouse oocytes. Dev Biol 288: 397-404.

Mehlmann LM. 2005b. Stops and starts in mammalian oocytes: Recent advances in understanding the regulation of meiotic arrest and oocyte maturation. Reproduction 130: 791-799.

Mehlmann LM, Jones TL, Jaffe LA. 2002. Meiotic arrest in the mouse follicle maintained by a $G_{s}$ protein in the oocyte. Science 297: 1343-1345.

Mehlmann LM, Saeki Y, Tanaka S, Brennan TJ, Evsikov AV, Pendola FL, Knowles BB, Eppig JJ, Jaffe LA. 2004. The $\mathrm{G}_{\mathrm{s}}$ linked receptor GPR3 maintains meiotic arrest in mammalian oocytes. Science 306: 1947-1950.

Miller MA, Nguyen VQ, Lee MH, Kosinski M, Schedl T, Caprioli RM, Greenstein D. 2001. A sperm cytoskeletal protein that signals oocyte meiotic maturation and ovulation. Science 291: 2144-2147.

Miller MA, Ruest PJ, Kosinski M, Hanks SK, Greenstein D. 2003. An Eph receptor sperm-sensing control mechanism for oocyte meiotic maturation in Caenorhabditis elegans. Genes Dev 17: 187-200.

Nishiyama TT, Kishimoto T. 2010. Cytostatic arrest: Postovulation arrest until fertilization in metazoan oocytes. Wiley, New York.

Norris RP, Freudzon M, Mehlmann LM, Cowan AE, Simon AM, Paul DL, Lampe PD, Jaffe LA. 2008. Luteinizing hormone causes MAP kinase-dependent phosphorylation and closure of connexin 43 gap junctions in mouse ovarian follicles: One of two paths to meiotic resumption. Development 135: 3229-3238.

Norris RP, Ratzan WJ, Freudzon M, Mehlmann LM, Krall J, Movsesian MA, Wang H, Ke H, Nikolaev VO, Jaffe LA. 2009. Cyclic GMP from the surrounding somatic cells regulates cyclic AMP and meiosis in the mouse oocyte. Development 136: 1869-1878.
Page SL, Hawley RS. 2001. c(3) G encodes a Drosophila synaptonemal complex protein. Genes Dev 15: 3130-3143.

Panigone S, Hsieh M, Fu M, Persani L, Conti M. 2008. Luteinizing hormone signaling in preovulatory follicles involves early activation of the epidermal growth factor receptor pathway. Mol Endocrinol 22: 924-936.

Parry JM, Velarde NV, Lefkovith AJ, Zegarek MH, Hang JS, Ohm J, Klancer R, Maruyama R, Druzhinina MK, Grant BD, et al. 2009. EGG-4 and EGG-5 link events of the oocyte-to-embryo transition with meiotic progression in C. elegans. Curr Biol 19: 1752-1757.

Peng XR, Hsueh AJ, LaPolt PS, Bjersing L, Ny T. 1991. Localization of luteinizing hormone receptor messenger ribonucleic acid expression in ovarian cell types during follicle development and ovulation. Endocrinology 129: 3200-3207.

Pesin JA, Orr-Weaver TL. 2007. Developmental role and regulation of cortex, a meiosis-specific anaphase-promoting complex/cyclosome activator. PLoS Genet 3: e202.

Piontkewitz Y, Dekel N. 1993. Heptanol, an alkanol that blocks gap junctions, induces oocyte maturation. Endocrine 1: 365-372.

Pirino G, Wescott MP, Donovan PJ. 2009. Protein kinase A regulates resumption of meiosis by phosphorylation of Cdc25B in mammalian oocytes. Cell Cycle 8: 665-670.

Racowsky C, Baldwin KV. 1989. In vitro and in vivo studies reveal that hamster oocyte meiotic arrest is maintained only transiently by follicular fluid, but persistently by membrana/cumulus granulosa cell contact. Dev Biol 134: 297-306.

Radford HE, Meijer HA, de Moor CH. 2008. Translational control by cytoplasmic polyadenylation in Xenopus oocytes. Biochim Biophys Acta 1779: 217-229.

Rauh NR, Schmidt A, Bormann J, Nigg EA, Mayer TU. 2005. Calcium triggers exit from meiosis II by targeting the APC/C inhibitor XErp1 for degradation. Nature 437: 1048-1052.

Ray RP, Schupbach T. 1996. Intercellular signaling and the polarization of body axes during Drosophila oogenesis. Genes Dev 10: 1711-1723.

Reis A, Chang HY, Levasseur M, Jones KT. 2006. APCcdh1 activity in mouse oocytes prevents entry into the first meiotic division. Nat Cell Biol 8: 539-540.

Resnick TD, Dej KJ, Xiang Y, Hawley RS, Ahn C, Orr-Weaver TL. 2009. Mutations in the chromosomal passenger complex and the condensin complex differentially affect synaptonemal complex disassembly and metaphase I configuration in Drosophila female meiosis. Genetics 181: 875-887.

Riechmann V, Ephrussi A. 2001. Axis formation during Drosophila oogenesis. Curr Opin Genet Dev 11: 374-383.

Rose KL, Winfrey VP, Hoffman LH, Hall DH, Furuta T, Greenstein D. 1997. The POU gene ceh-18 promotes gonadal sheath cell differentiation and function required for meiotic maturation and ovulation in Caenorhabditis elegans. Dev Biol 192: 59-77.

Roshak AK, Capper EA, Imburgia C, Fornwald J, Scott G, Marshall LA. 2000. The human polo-like kinase, PLK, regulates $\mathrm{cdc} 2 /$ cyclin $\mathrm{B}$ through phosphorylation and activation of the cdc25C phosphatase. Cell Signal 12: 405-411. 
Sackton KL, Lopez JM, Berman CL, Wolfner MF. 2009. YA is needed for proper nuclear organization to transition between meiosis and mitosis in Drosophila. BMC Dev Biol 9: 43.

Sagata N. 1996. Meiotic metaphase arrest in animal oocytes: Its mechanisms and biological significance. Trends Cell Biol 6: 22-28.

Schindler K, Schultz RM. 2009. CDC14B acts through FZR1 (CDH1) to prevent meiotic maturation of mouse oocytes. Biol Reprod 80: 795-803.

Sela-Abramovich S, Chorev E, Galiani D, Dekel N. 2005. Mitogen-activated protein kinase mediates luteinizing hormone-induced breakdown of communication and oocyte maturation in rat ovarian follicles. Endocrinology 146: $1236-1244$

Sela-Abramovich S, Edry I, Galiani D, Nevo N, Dekel N. 2006. Disruption of gap junctional communication within the ovarian follicle induces oocyte maturation. Endocrinology 147: 2280-2286.

Sela-Abramovich S, Galiani D, Nevo N, Dekel N. 2008. Inhibition of rat oocyte maturation and ovulation by nitric oxide: Mechanism of action. Biol Reprod 78: 1111-1118.

Stebbings LA, Todman MG, Phillips R, Greer CE, Tam J, Phelan P, Jacobs K, Bacon JP, Davies JA. 2002. Gap junctions in Drosophila: Developmental expression of the entire innexin gene family. Mech Dev 113: 197-205.

Stitzel ML, Pellettieri J, Seydoux G. 2006. The C. elegans DYRK kinase MBK-2 marks oocyte proteins for degradation in response to meiotic maturation. Curr Biol 16: $56-62$.

Stitzel ML, Cheng KC, Seydoux G. 2007. Regulation of MBK-2/Dyrk kinase by dynamic cortical anchoring during the oocyte-to-zygote transition. Curr Biol 17: 15451554.

Sun QY, Miao YL, Schatten H. 2009. Towards a new understanding on the regulation of mammalian oocyte meiosis resumption. Cell Cycle 8: 2741-2747.

Swan A, Schupbach T. 2007. The Cdc20 (Fzy)/Cdh1-related protein, Cort, cooperates with Fzy in cyclin destruction and anaphase progression in meiosis I and II in Drosophila. Development 134: 891-899.

Tadros W, Goldman AL, Babak T, Menzies F, Vardy L, OrrWeaver T, Hughes TR, Westwood JT, Smibert CA, Lipshitz HD. 2007. SMAUG is a major regulator of maternal mRNA destabilization in Drosophila and its translation is activated by the PAN GU kinase. Dev Cell 12: 143-155.

Takeo S, Tsuda M, Akahori S, Matsuo T, Aigaki T. 2006. The calcineurin regulator sra plays an essential role in female meiosis in Drosophila. Curr Biol 16: 1435-1440.

Takeo S, Hawley RS, Aigaki T. 2010. Calcineurin and its regulation by Sra/RCAN is required for completion of meiosis in Drosophila. Dev Biol 344: 957-967.

Tatone C, Delle Monache S, Iorio R, Caserta D, Di Cola M, Colonna R. 2002. Possible role for $\mathrm{Ca}^{2+}$ calmodulindependent protein kinase II as an effector of the fertilization $\mathrm{Ca}^{2+}$ signal in mouse oocyte activation. Mol Hum Reprod 8: 750-757.
Tootle TL, Spradling AC. 2008. Drosophila Pxt: A cyclooxygenase-like facilitator of follicle maturation. Development 135: 839-847.

Tsurumi C, Hoffmann S, Geley S, Graeser R, Polanski Z. 2004. The spindle assembly checkpoint is not essential for CSF arrest of mouse oocytes. J Cell Biol 167: $1037-1050$.

Tunquist BJ, Maller JL. 2003. Under arrest: Cytostatic factor (CSF)-mediated metaphase arrest in vertebrate eggs. Genes Dev 17: 683-710.

Vaccari S, Horner K, Mehlmann LM, Conti M. 2008. Generation of mouse oocytes defective in cAMP synthesis and degradation: Endogenous cyclic AMP is essential for meiotic arrest. Dev Biol 316: 124-134.

Vaccari S, Weeks JL, 2nd, Hsieh M, Menniti FS, Conti M. 2009. Cyclic GMP signaling is involved in the luteinizing hormone-dependent meiotic maturation of mouse oocytes. Biol Reprod 81: 595-604.

Vardy L, Orr-Weaver TL. 2007a. The Drosophila PNG kinase complex regulates the translation of cyclin B. Dev Cell 12: $157-166$.

Vardy L, Orr-Weaver TL. 2007b. Regulating translation of maternal messages: multiple repression mechanisms. Trends Cell Biol 17: 547-554.

Verlhac MH, Kubiak JZ, Weber M, Geraud G, Colledge WH, Evans MJ, Maro B. 1996. Mos is required for MAP kinase activation and is involved in microtubule organization during meiotic maturation in the mouse. Development 122: $815-822$.

Von Stetina JR, Tranguch S, Dey SK, Lee LA, Cha B, Drummond-Barbosa D. 2008. $\alpha$-Endosulfine is a conserved protein required for oocyte meiotic maturation in Drosophila. Development 135: 3697-3706.

Whitaker M. 1996. Control of meiotic arrest. Rev Reprod 1: $127-135$.

White-Cooper H, Alphey L, Glover DM. 1993. The cdc25 homologue twine is required for only some aspects of the entry into meiosis in Drosophila. J Cell Sci 106: 1035-1044.

Whitten SJ, Miller MA. 2007. The role of gap junctions in Caenorhabditis elegans oocyte maturation and fertilization. Dev Biol 301: 432-446.

Xiang Y, Takeo S, Florens L, Hughes SE, Huo LJ, Gilliland WD, Swanson SK, Teeter K, Schwartz JW, Washburn MP, et al. 2007. The inhibition of polo kinase by matrimony maintains $G_{2}$ arrest in the meiotic cell cycle. PLoS Biol 5: e323.

Yamamoto I, Kosinski ME, Greenstein D. 2006. Start me up: Cell signaling and the journey from oocyte to embryo in C. elegans. Dev Dyn 235: 571-585.

Yu J, Fleming SL, Williams B, Williams EV, Li Z, Somma P, Rieder CL, Goldberg ML. 2004. Greatwall kinase: A nuclear protein required for proper chromosome condensation and mitotic progression in Drosophila. J Cell Biol 164: 487-492.

Zhang M, Su YQ, Sugiura K, Xia G, Eppig JJ. 2010. Granulosa cell ligand NPPC and its receptor NPR2 maintain meiotic arrest in mouse oocytes. Science 330: 366-369. 


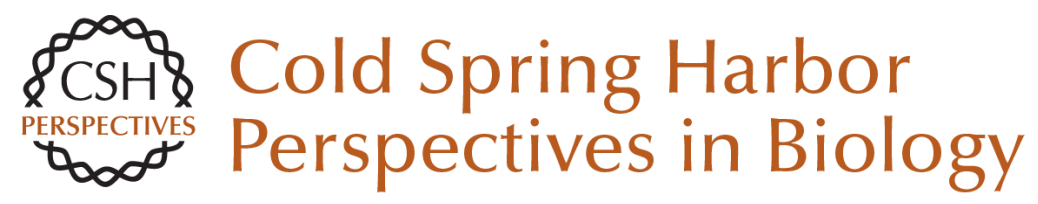

\title{
Developmental Control of Oocyte Maturation and Egg Activation in Metazoan Models
}

\author{
Jessica R. Von Stetina and Terry L. Orr-Weaver
}

Cold Spring Harb Perspect Biol 2011; doi: 10.1101/cshperspect.a005553 originally published online June 27,2011

\section{Subject Collection Germ Cells}

\section{RNA Granules in Germ Cells}

Ekaterina Voronina, Geraldine Seydoux, Paolo

Sassone-Corsi, et al.

Function of the Sex Chromosomes in Mammalian

Fertility

Edith Heard and James Turner

Small Noncoding RNAs in the Germline Jonathan P. Saxe and Haifan Lin

Mammalian Genomic Imprinting

Marisa S. Bartolomei and Anne C. Ferguson-Smith

Molecular Regulation of the Mitosis/Meiosis

Decision in Multicellular Organisms Judith Kimble

Selection in the Rapid Evolution of Gamete

Recognition Proteins in Marine Invertebrates Victor D. Vacquier and Willie J. Swanson
Developmental Control of Oocyte Maturation and

Egg Activation in Metazoan Models Jessica R. Von Stetina and Terry L. Orr-Weaver

Translational Control in Oocyte Development Joel D. Richter and Paul Lasko

Unique Aspects of Transcription Regulation in Male Germ Cells Helen White-Cooper and Irwin Davidson

Germ Cell Intercellular Bridges Michael P. Greenbaum, Tokuko Iwamori, Gregory M. Buchold, et al.

Germline Stem Cells

Allan Spradling, Margaret T. Fuller, Robert E. Braun, et al.

Nuclear Transfer to Eggs and Oocytes J. B. Gurdon and lan Wilmut

For additional articles in this collection, see http://cshperspectives.cshlp.org/cgi/collection/

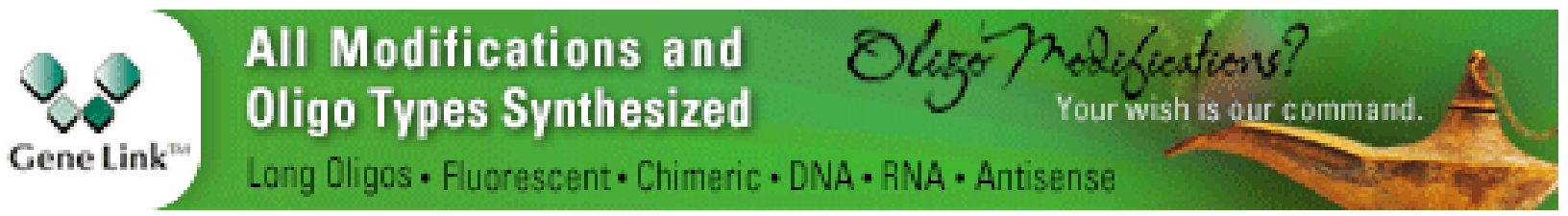

Copyright @ 2011 Cold Spring Harbor Laboratory Press; all rights reserved 